\title{
Increasing the Value of Orthodontic Research Through the Use of Dental Patient-Reported Outcomes
}

DOI:

10.1016/j.jebdp.2019.04.005

\section{Document Version}

Accepted author manuscript

Link to publication record in Manchester Research Explorer

\section{Citation for published version (APA):}

Hua, F. (2019). Increasing the Value of Orthodontic Research Through the Use of Dental Patient-Reported Outcomes. Journal of Evidence-Based Dental Practice. https://doi.org/10.1016/j.jebdp.2019.04.005

\section{Published in:}

Journal of Evidence-Based Dental Practice

\section{Citing this paper}

Please note that where the full-text provided on Manchester Research Explorer is the Author Accepted Manuscript or Proof version this may differ from the final Published version. If citing, it is advised that you check and use the publisher's definitive version.

\section{General rights}

Copyright and moral rights for the publications made accessible in the Research Explorer are retained by the authors and/or other copyright owners and it is a condition of accessing publications that users recognise and abide by the legal requirements associated with these rights.

\section{Takedown policy}

If you believe that this document breaches copyright please refer to the University of Manchester's Takedown Procedures [http://man.ac.uk/04Y6Bo] or contact uml.scholarlycommunications@manchester.ac.uk providing relevant details, so we can investigate your claim.

\section{OPEN ACCESS}




\title{
Increasing the Value of Orthodontic Research Through the Use of Dental Patient-Reported Outcomes
}

\author{
Fang Hua ${ }^{a, b}$ \\ ${ }^{a}$ Center for Evidence-Based Stomatology \& Department of Orthodontics, Hubei-MOST KLOS \& \\ KLOBM, School \& Hospital of Stomatology, Wuhan University, Wuhan, China \\ ${ }^{b}$ Division of Dentistry, School of Medical Sciences, Faculty of Biology, Medicine and Health, The \\ University of Manchester, Manchester Academic Health Science Centre, Manchester, UK
}

Corresponding author:

Fang Hua, School \& Hospital of Stomatology, Wuhan University, 237 Luoyu Road, Wuhan 430079, China

E-mail: huafang@whu.edu.cn

\section{How to Cite:}

Hua F. Increasing the Value of Orthodontic Research Through the Use of Dental Patient-Reported Outcomes. Journal of Evidence-Based Dental Practice, 2019. doi: 10.1016/j.jebdp.2019.04.005 [Epub ahead of print].

doi: $10.1016 /$ j.jebdp.2019.04.005

Please note that this is a post-print version (after peer-review) for the purpose of selfarchiving. Please download the final published version from the publisher's website: https://www.sciencedirect.com/science/article/pii/S1532338219300806 


\section{Abstract}

Ten years ago, Chalmers and Glasziou pointed out in Lancet that $85 \%$ of all biomedical research was being avoidably wasted due to imbalanced research question / outcome selection, as well as poor study design, execution and reporting. According to findings of recent "research on research" studies, a high level of such kind of avoidable waste should also exist in orthodontic research. This warrants efforts to improve each stage of the research production and reporting process.

Nowadays, patients' psycho-social function is considered a core element of oral health. Also, their treatment needs and preferences have formed a main component of evidence-based dentistry (EBD). Therefore, in order to achieve shared decision-making, orthodontists need to have an adequate understanding of each patient's values and perceptions.

In this context, orthodontic research should be patient-centered so that the knowledge and perception gaps between clinicians and patients can be reduced, and research evidence that is suitable for patients to understand can be provided. In addition, patient-centered outcomes that can reflect patients' perceptions and psycho-social status should be widely used.

However, recent scoping reviews have shown that during the past decade, patientcentered outcomes including those regarding adverse effects, health service resource utilization and quality of life have remained underrepresented in orthodontic trials. Thus, the use of dental patient-reported outcomes (dPROs) and dental patientreported outcome measures ( $\mathrm{dPROMs}$ ) should be promoted to facilitate the provision of a patient-centered evidence base, reduce the avoidable waste related to research question / outcome selection, and thereby increase the value of orthodontic research. 


\section{Avoidable Waste in Orthodontic Research}

Just ten years ago, Chalmers and Glasziou ${ }^{1}$ pointed out in Lancet that a majority of all biomedical research was being avoidably wasted due to imbalanced research question / outcome selection, inadequate study design and execution, non-publication, lack of accessibility, and poor reporting. As over $50 \%$ of studies failed to take adequate steps to reduce biases (e.g. inadequate allocation concealment), ${ }^{2}$ over $50 \%$ of studies were never published in full, ${ }^{3}$ and more than $50 \%$ of planned study outcomes were not reported, ${ }^{4}$ they estimated that the proportion of such waste was greater than $85 \%{ }^{1}$ Thereafter, the Lancet launched the REWARD (REduce research Waste And Reward Diligence) campaign and published a series of five reviews regarding "increasing value and reducing waste", each covering one stage in the production and reporting of biomedical research (Figure)..$^{5,6}$

In orthodontics, recent "research on research" studies have found that about $70 \%$ of randomized controlled trials (RCTs) did not have adequate allocation concealment, ${ }^{7} 50 \%$ of studies were never fully published, ${ }^{8}$ and more than $80 \%$ of RCTs did not adequately report their pre-specified primary outcome measures. ${ }^{9}$ Based on these findings and the calculation method used by Chalmers and Glasziou, ${ }^{1}$ the estimated proportion of avoidable waste in orthodontic research would be even higher than $85 \%$. This looks appalling, but still it has not taken into account the fact that over $60 \%$ of orthodontic RCTs were focused on outcomes that were irrelevant to patients, ${ }^{10}$ and that more than $30 \%$ of orthodontic papers were not freely available online for clinicians and patients (Figure). ${ }^{11}$

Undoubtedly, such a high level of avoidable waste warrants efforts to improve all five stages of the production and reporting of orthodontic research. This article will discuss potential measures to take for the first stage and, more specifically, the significance of patient-centered research and dental patient-reported outcomes (dPROs) for orthodontics.

\section{Patients' Perceptions and the Definition of Oral Health}

Recognition of the importance of patients' perception can be traced back to the 
addition of "social well-being" into the WHO definition of health in 1940s, which led to a paradigm shift in the model of health from biomedical to biopsychosocial. ${ }^{12}$ Thereafter, similar modifications were made to the definition of oral health. In 1993, Dolan defined oral health (for older populations) as "a comfortable and functional dentition which allows individuals to continue in their desired social role". ${ }^{13}$ More recently, the FDI World Dental Federation developed a new definition for oral health:

"Oral health is multifaceted and includes the ability to speak, smile, smell, taste, touch, chew, swallow, and convey a range of emotions through facial expressions with confidence and without pain, discomfort, and disease of the craniofacial complex."14

In addition, the FDI World Dental Federation emphasized that oral health "reflects the physiological, social and psychological attributes that are essential to the quality of life (QoL)," and "is influenced by the person's changing experiences, perceptions, expectations, and ability to adapt to circumstances." ${ }^{14}$ These definitions have all importantly indicated that the goals of dental health care should include not only the treatment of patients' diseases / conditions, but also the improvement / restoration of their physiological and psycho-social functions. To achieve these, it is essential that dental professionals including orthodontists have an adequate understanding of their patients' perceptions and expectations, both at an individual level and a population level.

\section{Evidence-Based Medicine and Evidence-Based Dentistry}

A common criticism of evidence-based medicine (EBM) has been that EBM means "cookbook medicine" and decision-making based on evidence alone, without necessary deliberation and reasoning. ${ }^{15}$ However, as experts in $\mathrm{EBM}{ }^{16}$ and evidencebased orthodontics (EBO) ${ }^{17}$ have pointed out, such an argument is merely a misunderstanding of what EBM is. In effect, the need to consider each patient's values has been aggressively promoted since the very early years of EBM. ${ }^{16}$

In 1996, Sacket and colleagues already stated that:

"EBM is the conscientious, explicit, and judicious use of current best evidence in 
making decisions about the care of individual patients. The practice of EBM means integrating individual clinical expertise with the best available external clinical evidence from systematic research. ... Increased expertise is reflected in many ways, but especially in more effective and efficient diagnosis and in the more thoughtful identification and compassionate use of individual patients' predicaments, rights, and preferences in making clinical decisions about their care. $^{\prime 18}$

Months later, they went on to propose a simple model for evidence-based decisionmaking, with clinicians' expertise, patients' preferences and research evidence being the three main components of this model. ${ }^{19}$ In 1999, these components were adopted by the American Dental Association (ADA) for its official definition of evidence-based dentistry (EBD):

"EBD is an approach to oral healthcare that requires the judicious integration of systematic assessments of clinically relevant scientific evidence, relating to the patient's oral and medical condition and history, with the dentist's clinical expertise and the patient's treatment needs and preferences."20, 21

The emphasis that EBM and EBD place on patients is in accordance with a cultural change in medicine over the past decades: the increasing importance of patients' autonomy and consent, as well as the associated demand for shared decision-making (SDM) and patient-centered care. ${ }^{16,22}$

\section{Shared Decision-Making in Orthodontic Practice}

According to Gatellari et $a l,{ }^{23}$ SDM is a decision-making process in which clinicians and patients are equal partners and are required to exchange information and preferences in order to negotiate a mutually acceptable treatment decision. In the case of orthodontics, this approach is particularly important for many reasons. Some of the main ones are as follows.

First, as malocclusion is not a disease but a variation from the societal norm, ${ }^{24}$ orthodontic treatment is often elective. ${ }^{25}$ Plus, orthodontic treatment is not without risks / adverse effects (e.g. root resorption, enamel demineralization). ${ }^{26}$ The SDM 
approach can facilitate thorough exchange of expectations, preferences and possible treatment outcomes between orthodontists and patients, and thereby help them determine whether orthodontic treatment is able to achieve the intended effect, and whether the potential gain outweigh risks and costs.

Second, orthodontic patients usually expect to improve their dentofacial appearance through orthodontic treatment. ${ }^{27}$ However, the patients' perception of esthetics is often different from that of orthodontists. For instance, patients seem to be more tolerant / less sensitive than orthodontists towards gummy smile, ${ }^{28}$ midline discrepancies, ${ }^{29}$ and white spot lesions. ${ }^{30}$ In light of such discrepancies, orthodontists should use the SDM approach to obtain an adequate understanding of the patient's expectation and treatment need. A personalized treatment goal that is acceptable to both parties could then be set and achieved.

In addition, like in other dental specialties, for each orthodontic problem there usually exist multiple therapies / techniques that can be considered. ${ }^{31}$ Examples include different types of appliances (e.g. conventional brackets, self-ligating brackets, clear aligners), methods to relieve crowding (e.g. tooth extraction, interproximal reduction, total arch distalization), and methods to reinforce anchorage (e.g. miniscrews, transpalatal arch, headgear). However, since many systematic reviews in orthodontics failed to perform meaningful meta-analyses (mostly due to low quantity and quality of eligible studies, as well as the use of heterogeneous outcome measures), orthodontists are often faced with indefinite or conflicting evidence when comparing the available therapies / techniques. ${ }^{32}$ In this kind of situations, SDM is particularly needed so that clinician's expertise and patients' values / preferences can be well integrated and lead to the most suitable clinical decision. ${ }^{33}$

\section{Patient-Centered Research and Patient-Centered Outcomes}

The ultimate goal of all medical research is to improve our knowledge underpinning the prevention and treatment of illness. ${ }^{34}$ In the context of EBD, dental studies should be designed, executed and reported properly, so that their findings are relevant, valid and usable, facilitating the achievement and development of patient-centered, 
evidence-based dental practice. Towards this end, the research questions of dental studies should be relevant to patients, the outcomes that they use should be able to reflect patients' values and perceptions. ${ }^{35}$

In 2013, Tsichlaki and O'Brien ${ }^{10}$ carried out a scoping review to analyze the outcomes used in orthodontic RCTs during 2008 - 2012. They found that $63 \%$ of these trials were focused on assessing morphologic changes of malocclusion; whereas patient-centered outcomes including those regarding adverse effects, health service resource utilization and QoL were only measured in $32 \%, 32 \%$ and $9 \%$ of the included trials, respectively.

In 2017, Tsichlaki and colleagues ${ }^{36}$ updated the above-mentioned scoping review, as the first stage of developing a core outcome set (i.e. an agreed, minimum set of outcomes to be measured and reported) for orthodontic trials. ${ }^{37} \mathrm{~A}$ total of 54 different outcomes covering 14 outcome domains were identified, with half of the outcomes assessed by multiple outcome measures (range: 2 to 6). Although patient-reported pain was the most frequently used outcome (18\%), the authors found that most of the outcomes were still focused on the assessment of morphologic changes, with QoL measured by only $4(2 \%)$ of the included trials.

These data have shown a problem with the current selection of outcomes in orthodontic studies. As pointed out by $\mathrm{O}^{\prime} \mathrm{Brien}^{38}$ although those clinician-centered outcomes that orthodontic researchers traditionally measure (e.g. changes in overjet or the ANB angle) can be easily collected from study casts, radiographs, patient records and clinical examinations, they can neither reflect patients' perceptions and values, nor demonstrate how well an intervention can improve the patient's oral health. Studies that only assess clinician-centered outcomes may be ignoring or missing the acceptability of each intervention, i.e. the benefits and drawbacks of an intervention from the patient's perspective.

In an article published in The New England Journal of Medicine, Porter ${ }^{39}$ proposed a three-tiered hierarchy of outcome measures that can cover health circumstances relevant to patients, including the health status achieved or retained (tier 1), process of recovery (tier 2), and sustainability of health (tier 3 ). He emphasized that the value 
of health care should always be defined around patients, and the only way to measure this value accurately is to track patient outcomes and costs longitudinally, with a follow-up long enough to encompass the ultimate results of care.

Furthermore, in order to achieve and improve SDM, we need more patient-centered research that can reduce the gap in knowledge and perceptions between clinicians and patients, providing research evidence that is suitable for patients to understand. ${ }^{31}$ Promoting the use of dPROs in orthodontic research could be one step further towards the provision of such a patient-centered evidence base. ${ }^{25}$

\section{Dental Patient-Reported Outcomes and Dental Patient-Reported} Outcome Measures

dPROs, a term recently coined by John, ${ }^{40}$ are defined as "any report of the status of a patient's oral health condition that comes directly from the patient, without interpretation of the patient's response by a clinician or anyone else." Just like oral health is a component of general health, dPROs are a subset of all patient-reported outcomes (PROs). dPROs can capture the impact of conditions or interventions on oral health, while dental patient-reported outcome measures (dPROMs) are used to assess this impact and express it numerically. ${ }^{40}$

In a recent systematic review, John and colleagues ${ }^{41}$ analyzed the existing multi-item, generic dPROMs for adult dental patients. Based on 20 eligible questionnaires (e.g. the Oral Health Impact Profile), they identified 53 dPROMs, which represent all currently available multi-item instruments for assessing the perceived oral health of patients. $A$ total of 36 unique dPROs were assessed by these dPROMs, including 35 narrower dPROs (e.g. functional limitations, physical pain, psychological discomfort) and 1 broader dPRO - the oral health-related quality of life (OHRQoL). Also, the authors found that those 35 narrower dPROs can be categorized into four groups: Oral Function, Orofacial Appearance, Orofacial Pain, and Psychosocial Impact. This is in accordance with the four dimensions of OHRQoL, ${ }^{42,43}$ indicating that these dPROs have covered all major concerns of dental patients with their oral health. ${ }^{41}$ 
In an earlier article of this series, Reissmann ${ }^{44}$ introduced several additional advantages of dPROMs over disease-oriented outcome measures for research: 1) better reliability and the resultant smaller required sample size; 2) flexible administration and easy data collection; 3 ) lower workload and higher efficiency; 4) providing information about the entire patient; and 5) easy interpretation and sample size calculation (when the minimal important difference is available).

\section{Oral Health-Related Quality of Life and Orthodontic Research}

As mentioned above, OHRQoL is a major $\mathrm{APRO}$, and each OHRQoL instrument can be seen as a dPROM or a combination of several dPROMs (depending on the number of dimensions the instrument contains). ${ }^{41}$ During the past twenty years, orthodontic researchers have carried out many epidemiological studies regarding OHRQoL. ${ }^{45}$ Based on these, recent systematic reviews have concluded that malocclusion has a significant (though small) negative impact on the OHRQoL of children (mainly in the emotional and social well-being dimensions), ${ }^{46-48}$ and that orthodontic treatment can lead to moderate but significant improvement in OHRQoL. ${ }^{49,50}$ Despite the low quality evidence underlying these reviews (mainly due to inadequate study design and substantial heterogeneity), they have demonstrated the capability of OHRQoL to reflect orthodontic treatment need and the benefits of orthodontic interventions to patients. Unfortunately, so far very few clinical studies in orthodontics have used OHRQoL as their primary or secondary outcome, especially those RCTs. ${ }^{10,} 36$ Nevertheless, an opportunity to solve this problem may arise in the near future, once the core outcome set for orthodontic research (which includes OHRQoL related dPROMs) is completed and available. ${ }^{37}$

In addition, another relevant issue is the large number of OHRQoL instruments that have been used in orthodontic research. For instance, among studies with regard to the association between malocclusion and OHRQoL, at least eight different instruments have been used. ${ }^{47}$ Such a lack of standardization brings difficulties to the interpretation and syntheses of different studies, and is therefore unhelpful for SDM and patient-centered care (even though dPROMs have been used). Again, a core outcome set may be the key to this issue if it includes only one OHRQoL instrument 
for each possible situation (e.g. different age groups). Such an instrument may be selected / modified from the existing tools based on their scope and psychometric properties, $^{43,44}$ or be developed specifically for the context of malocclusion / orthodontics based on perceptions of the target population. ${ }^{51,52}$

\section{Summary}

Patients' psycho-social function is a core element of oral health; their treatment needs and preferences form a main component of EBD. However, recent studies have shown that most of the outcomes measured in orthodontic trials are focused on assessing morphologic changes, whereas patient-centered outcomes have remained underrepresented. In light of this, the use of dPROs and dPROMs should be promoted to facilitate the provision of a patient-centered evidence base, reduce the avoidable waste related to research question / outcome selection, and thereby increase the value of orthodontic research. 


\section{References}

1. Chalmers I, Glasziou P. Avoidable waste in the production and reporting of research evidence. Lancet. 2009;374:86-89.

2. Hewitt C, Hahn S, Torgerson DJ, Watson J, Bland JM. Adequacy and reporting of allocation concealment: review of recent trials published in four general medical journals. BMJ. 2005;330:1057-1058.

3. Scherer RW, Langenberg $P$, von Elm E. Full publication of results initially presented in abstracts. Cochrane Database Syst Rev. 2007:MR000005.

4. Dwan K, Altman DG, Arnaiz JA, et al. Systematic review of the empirical evidence of study publication bias and outcome reporting bias. PLoS One. 2008;3:e3081.

5. Macleod MR, Michie S, Roberts I, et al. Biomedical research: increasing value, reducing waste. Lancet. 2014;383:101-104.

6. Moher D, Glasziou P, Chalmers I, et al. Increasing value and reducing waste in biomedical research: who's listening? Lancet. 2016;387:1573-1586.

7. Koletsi D, Spineli LM, Lempesi E, Pandis N. Risk of bias and magnitude of effect in orthodontic randomized controlled trials: a meta-epidemiological review. Eur J Orthod. 2016;38:308-312.

8. Livas C, Pandis N, Ren Y. Full-text publication of abstracts presented at European Orthodontic Society congresses. Eur J Orthod. 2014;36:569-575.

9. Sandhu SS, Sandhu J, Kaur H. Reporting quality of randomized controlled trials in orthodontics-what affects it and did it improve over the last 10 years? Eur J Orthod. 2014;37:356-366.

10. Tsichlaki A, O'Brien K. Do orthodontic research outcomes reflect patient values? A systematic review of randomized controlled trials involving children. Am J Orthod Dentofacial Orthop. 2014;146:279-285.

11. Hua F, Sun $H$, Walsh $T$, Worthington $H$, Glenny A-M. Open access to journal articles in dentistry: prevalence and citation impact. J Dent. 2016;47:41-48.

12. Baiju RM, Peter E, Varghese NO, Sivaram R. Oral Health and quality of life: Current concepts. J Clin Diagn Res. 2017;11:ZE21-ZE26.

13. Dolan TA. Identification of appropriate outcomes for an aging population. Spec Care Dentist. 1993;13:35-39.

14. Glick M, Williams DM, Kleinman DV, Vujicic M, Watt RG, Weyant RJ. A new definition for oral health developed by the FDI World Dental Federation opens 
the door to a universal definition of oral health. J Am Dent Assoc. 2016;147:915-917.

15. Timmermans S, Mauck A. The promises and pitfalls of evidence-based medicine. Health Aff (Millwood). 2005;24:18-28.

16. Djulbegovic B, Guyatt GH. Progress in evidence-based medicine: a quarter century on. Lancet. 2017;390:415-423.

17. Huang GJ. Making the case for evidence-based orthodontics. Am J Orthod Dentofacial Orthop. 2004;125:405-406.

18. Sackett DL, Rosenberg WM, Gray JA, Haynes RB, Richardson WS. Evidence based medicine: what it is and what it isn't. BMJ. 1996;312:71-72.

19. Haynes RB, Sackett DL, Gray JM, Cook DJ, Guyatt GH. Transferring evidence from research into practice: 1 . The role of clinical care research evidence in clinical decisions. ACP J Club. 1996;125:A14-16.

20. Hutter J. The history of evidence-based dentistry in the ADA. J Evid Based Dent Pract. 2004;4:8-11.

21. Brignardello-Petersen R, Carrasco-Labra A, Glick M, Guyatt GH, Azarpazhooh A. A practical approach to evidence-based dentistry: understanding and applying the principles of EBD. J Am Dent Assoc. 2014;145:1105-1107.

22. Jerrold L. Litigation and legislation. Dento-legal and ethical observations on the last 100 years. Am J Orthod Dentofacial Orthop. 2015;147:S234-241.

23. Gattellari M, Butow PN, Tattersall MH. Sharing decisions in cancer care. Soc Sci Med. 2001;52:1865-1878.

24. Shaw WC, O'Brien KD, Richmond S. Quality control in orthodontics: factors influencing the receipt of orthodontic treatment. Br Dent J. 1991;170:66-68.

25. Sischo L, Broder HL. Oral health-related quality of life: what, why, how, and future implications. J Dent Res. 2011;90:1264-1270.

26. Talic NF. Adverse effects of orthodontic treatment: A clinical perspective. Saudi Dent J. 2011;23:55-59.

27. Yao J, Li DD, Yang YQ, McGrath CP, Mattheos N. What are patients' expectations of orthodontic treatment: a systematic review. BMC Oral Health. 2016;16:19.

28. Guo J, Gong H, Tian W, Tang W, Bai D. Alteration of gingival exposure and its aesthetic effect. J Craniofac Surg. 2011;22:909-913.

29. Johnston $C D$, Burden $D J$, Stevenson $M R$. The influence of dental to facial midline discrepancies on dental attractiveness ratings. Eur J Orthod. 
1999;21:517-522.

30. Huang GJ, Roloff-Chiang B, Mills BE, et al. Effectiveness of MI Paste Plus and PreviDent fluoride varnish for treatment of white spot lesions: a randomized controlled trial. Am J Orthod Dentofacial Orthop. 2013;143:31-41.

31. Faggion CM, Jr., Pachur T, Giannakopoulos NN. Patients' values in clinical decision-making. J Evid Based Dent Pract. 2017;17:177-183.

32. Koletsi $D$, Fleming PS, Eliades T, Pandis $N$. The evidence from systematic reviews and meta-analyses published in orthodontic literature. Where do we stand? Eur J Orthod. 2015;37:603-609.

33. Friedlander $\mathrm{AH}$, Rosenbluth $\mathrm{SC}$, Freymiller EG, Braddock $\mathrm{CH}, 3 \mathrm{rd}$. When clinical evidence is conflicted, who decides how to proceed? An opportunity for shared decision making. J Am Dent Assoc. 2015;146:713-714.

34. Altman DG, Moher D. Importance of transparent reporting of health research. In: Moher D, Altman DG, Schulz KF, Simera I, Wager E, eds. Guidelines for reporting health research: $A$ user's manual. West Sussex, UK: John Wiley \& Sons, Ltd.; 2014:3-13.

35. Fleming PS, Koletsi D, O'Brien K, Tsichlaki A, Pandis N. Are dental researchers asking patient-important questions? A scoping review. J Dent. 2016;49:9-13.

36. Tsichlaki A, O'Brien K, Johal A, Fleming PS. Orthodontic trial outcomes: Plentiful, inconsistent, and in need of uniformity? A scoping review. Am J Orthod Dentofacial Orthop. 2018;153:797-807.

37. Tsichlaki A, O'Brien K, Johal A, et al. Development of a core outcome set for orthodontic trials using a mixed-methods approach: protocol for a multicentre study. Trials. 2017;18:366.

38. O'Brien K. Orthodontic research: If we know the answers, are we asking the right questions? Semin Orthod. 2013;19:137-141.

39. Porter ME. What is value in health care? N Engl J Med. 2010;363:2477-2481.

40. John MT. Health outcomes reported by dental patients. J Evid Based Dent Pract. 2018;18:332-335.

41. Mittal H, John MT, Sekulić S, Theis-Mahon N, Rener-Sitar K. Patient-reported outcome measures for adult dental patients: A systematic review. J Evid Based Dent Pract. 2019:https://doi.org/10.1016/j.jebdp.2018.1010.1005.

42. John MT, Hujoel P, Miglioretti DL, LeResche L, Koepsell TD, Micheelis W. Dimensions of oral-health-related quality of life. J Dent Res. 2004;83:956-960. 
43. John MT, Reissmann DR, Celebic A, et al. Integration of oral health-related quality of life instruments. J Dent. 2016;53:38-43.

44. Reissmann DR. Dental patient-reported outcome measures are essential for evidence-based prosthetic dentistry. J Evid Based Dent Pract. 2019:https://doi.org/10.1016/j.jebdp.2019.1001.1003.

45. O'Brien K, Kay L, Fox D, Mandall N. Assessing oral health outcomes for orthodontics--measuring health status and quality of life. Community Dent Health. 1998;15:22-26.

46. Liu Z, McGrath C, Hagg U. The impact of malocclusion/orthodontic treatment need on the quality of life. A systematic review. Angle Orthod. 2009;79:585591.

47. Kragt L, Dhamo B, Wolvius EB, Ongkosuwito EM. The impact of malocclusions on oral health-related quality of life in children-a systematic review and metaanalysis. Clin Oral Investig. 2016;20:1881-1894.

48. Dimberg L, Arnrup K, Bondemark L. The impact of malocclusion on the quality of life among children and adolescents: a systematic review of quantitative studies. Eur J Orthod. 2015;37:238-247.

49. Javidi $H$, Vettore $M$, Benson PE. Does orthodontic treatment before the age of 18 years improve oral health-related quality of life? A systematic review and meta-analysis. Am J Orthod Dentofacial Orthop. 2017;151:644-655.

50. Andiappan M, Gao W, Bernabe E, Kandala NB, Donaldson AN. Malocclusion, orthodontic treatment, and the Oral Health Impact Profile (OHIP-14): Systematic review and meta-analysis. Angle Orthod. 2015;85:493-500.

51. Patel N, Hodges SJ, Hall M, Benson PE, Marshman Z, Cunningham SJ. Development of the Malocclusion Impact Questionnaire (MIQ) to measure the oral health-related quality of life of young people with malocclusion: part 1 qualitative inquiry. J Orthod. 2016;43:7-13.

52. Benson PE, Cunningham SJ, Shah N, et al. Development of the Malocclusion Impact Questionnaire (MIQ) to measure the oral health-related quality of life of young people with malocclusion: part 2 - cross-sectional validation. J Orthod. 2016;43:14-23. 


\section{Acknowledgements}

FH is supported by the China Postdoctoral Science Foundation (No. 2018M630884). 


\section{Figure Legend}

Figure. The five stages of research waste proposed by Chalmers and colleagues ${ }^{1,5,6}$ and relevant findings from "research on research" studies in orthodontics (in italics). ${ }^{7-11}$

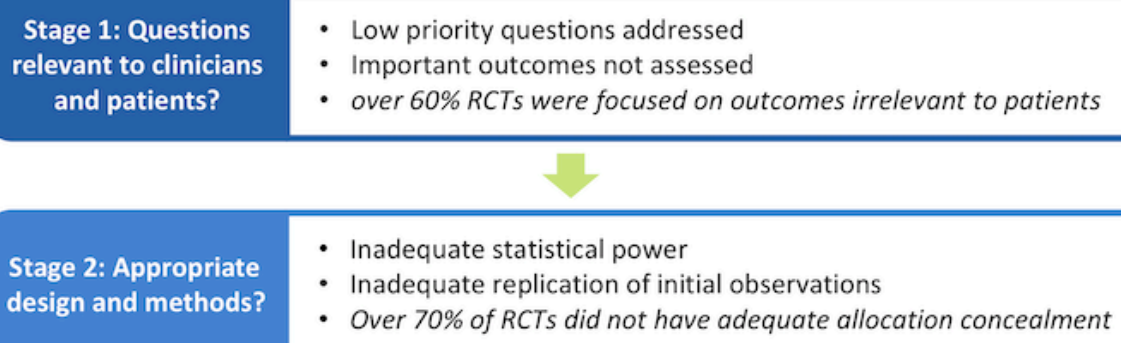

- Inadequate statistical power

- Inadequate replication of initial observations

- Over $70 \%$ of RCTs did not have adequate allocation concealment

Stage 3: Efficient research regulation and management? full research reports?
- Hyper-regulation of research

- Inefficient delivery of research

- Poor reuse of data

- Do not promote evaluative research as an integral element of good clinical practice
- Biased under-reporting of studies with disappointing results

- About $50 \%$ of studies were never fully published

- Over $30 \%$ of journal articles were not freely available online
Stage 5: Unbiased and useable reports?
- Most new research not interpreted in the context of relevant systematic reviews

- Over $80 \%$ of RCTs did not adequately report their pre-specified primary outcome measures 